\title{
S11 Dataset
}

Individual IEM images of 20 NPCs used for superimposed images of Figure 7 (inner ring Nups, channel Nups, cytoplasmic ring Nups, transmembrane Nups and nuclear basket Nups) 


\section{Nup93 subcomplex Nups}

Nup97,Npp106,Nup184,Nup186, Nup40, Nup155 


\section{GFP-Nup97}

projection

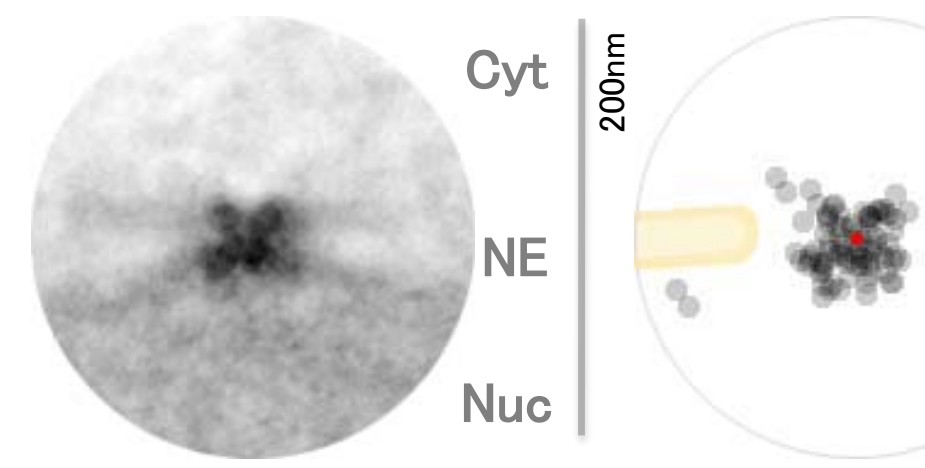

20 NPCs

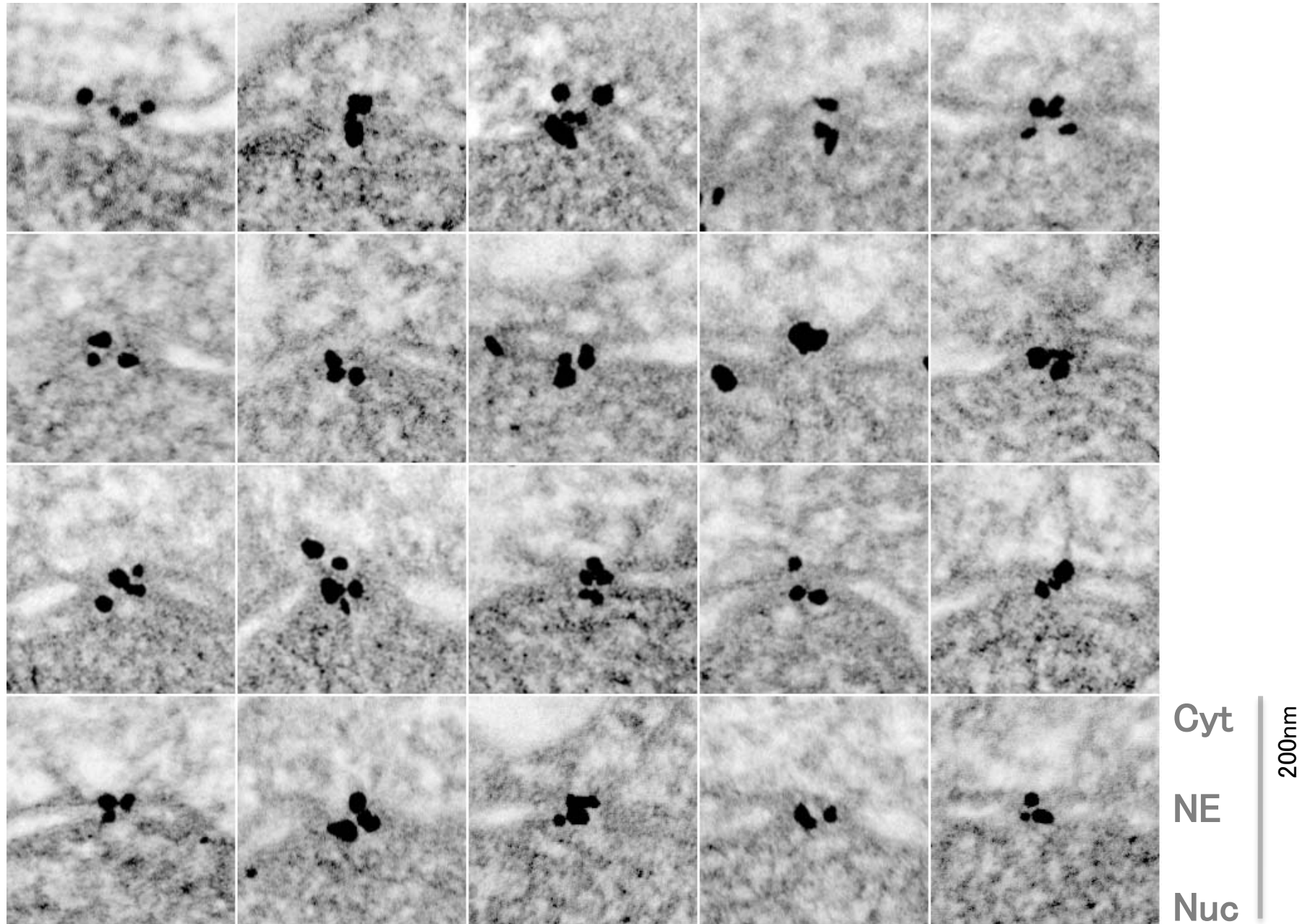




\section{GFP-Npp106}

projection

20 NPCs
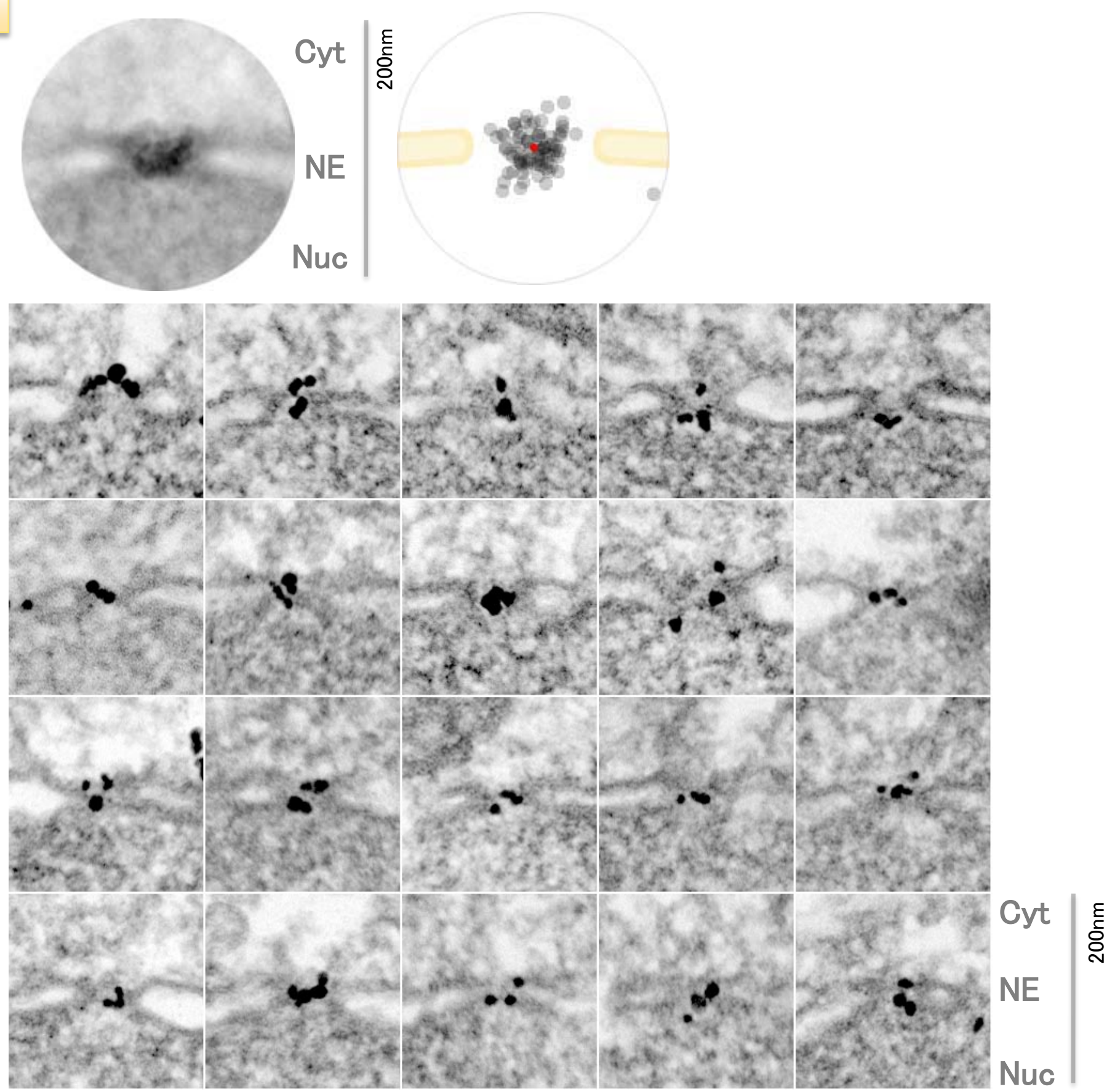


\section{GFP-Nup184}

projection

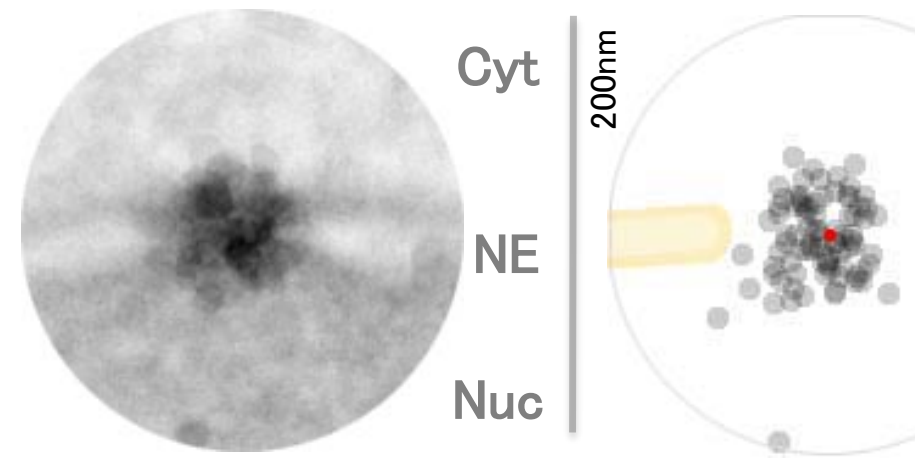

$20 \mathrm{NPCs}$

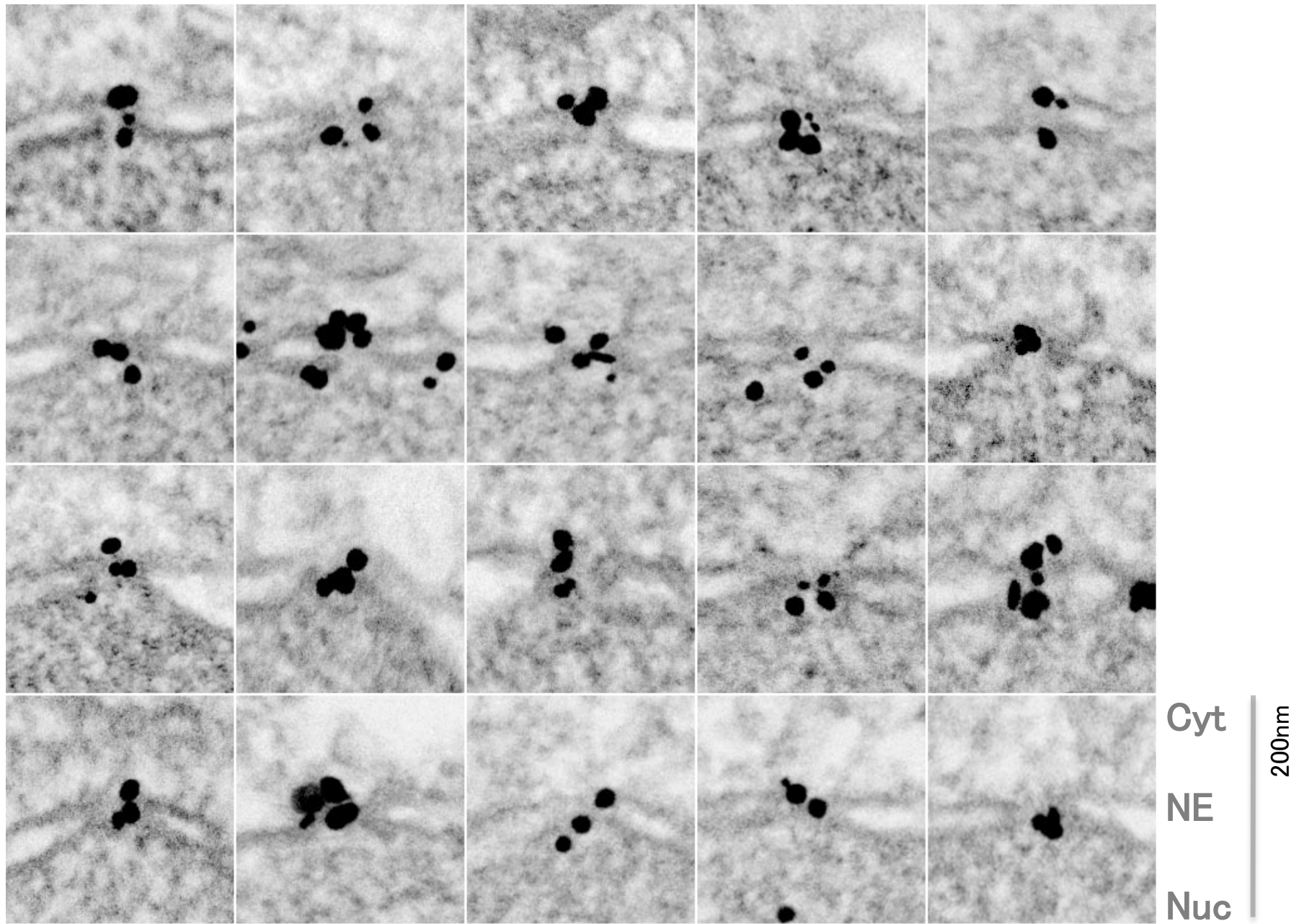




\section{GFP-Nup186}

projection

$20 \mathrm{NPCs}$
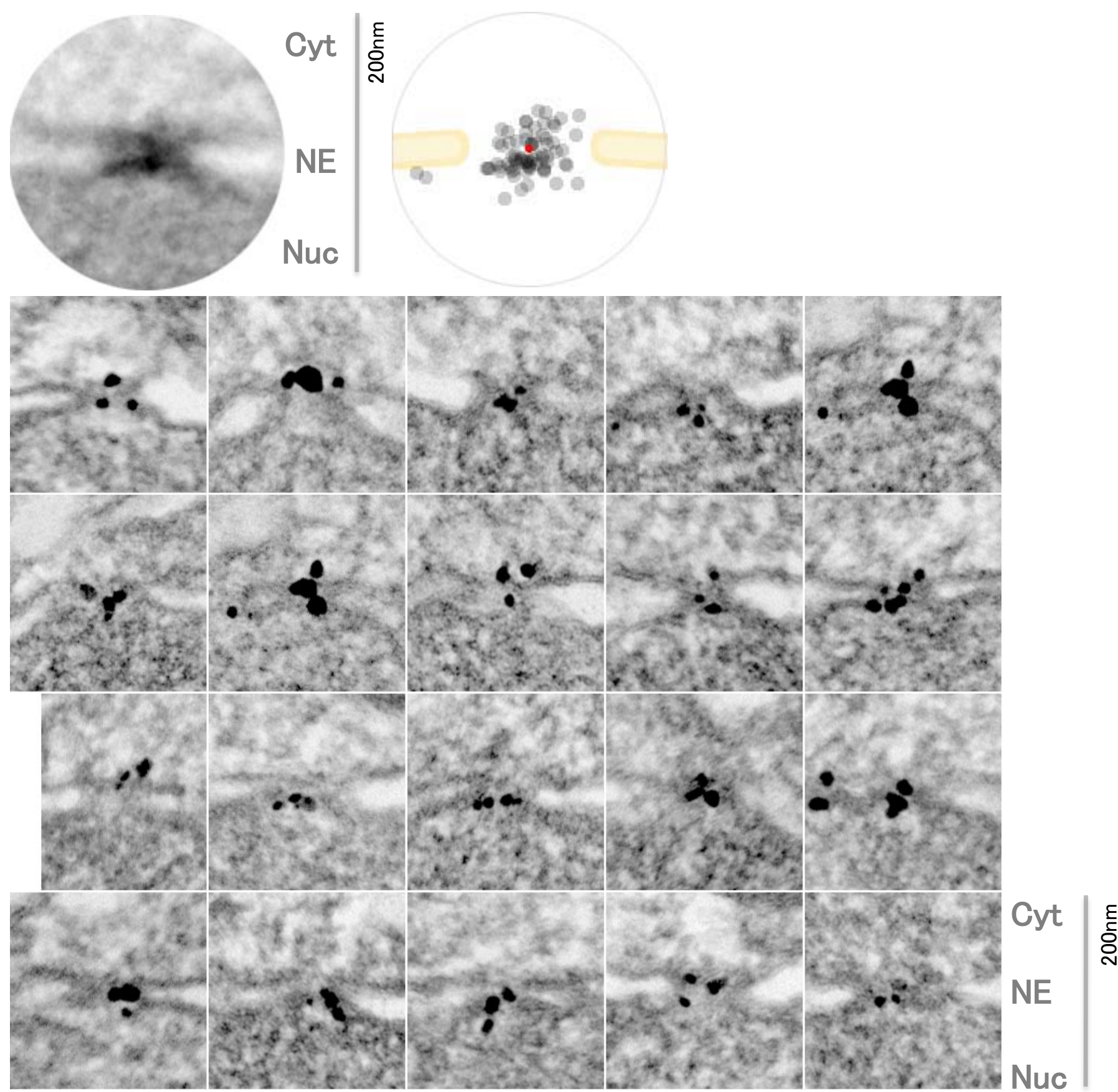


\section{GFP-Nup40}

projection

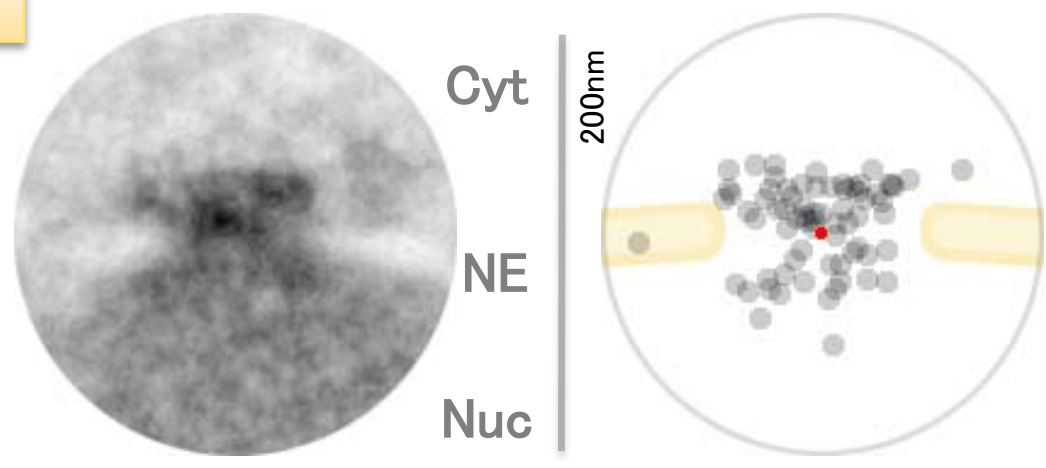

$20 \mathrm{NPCs}$

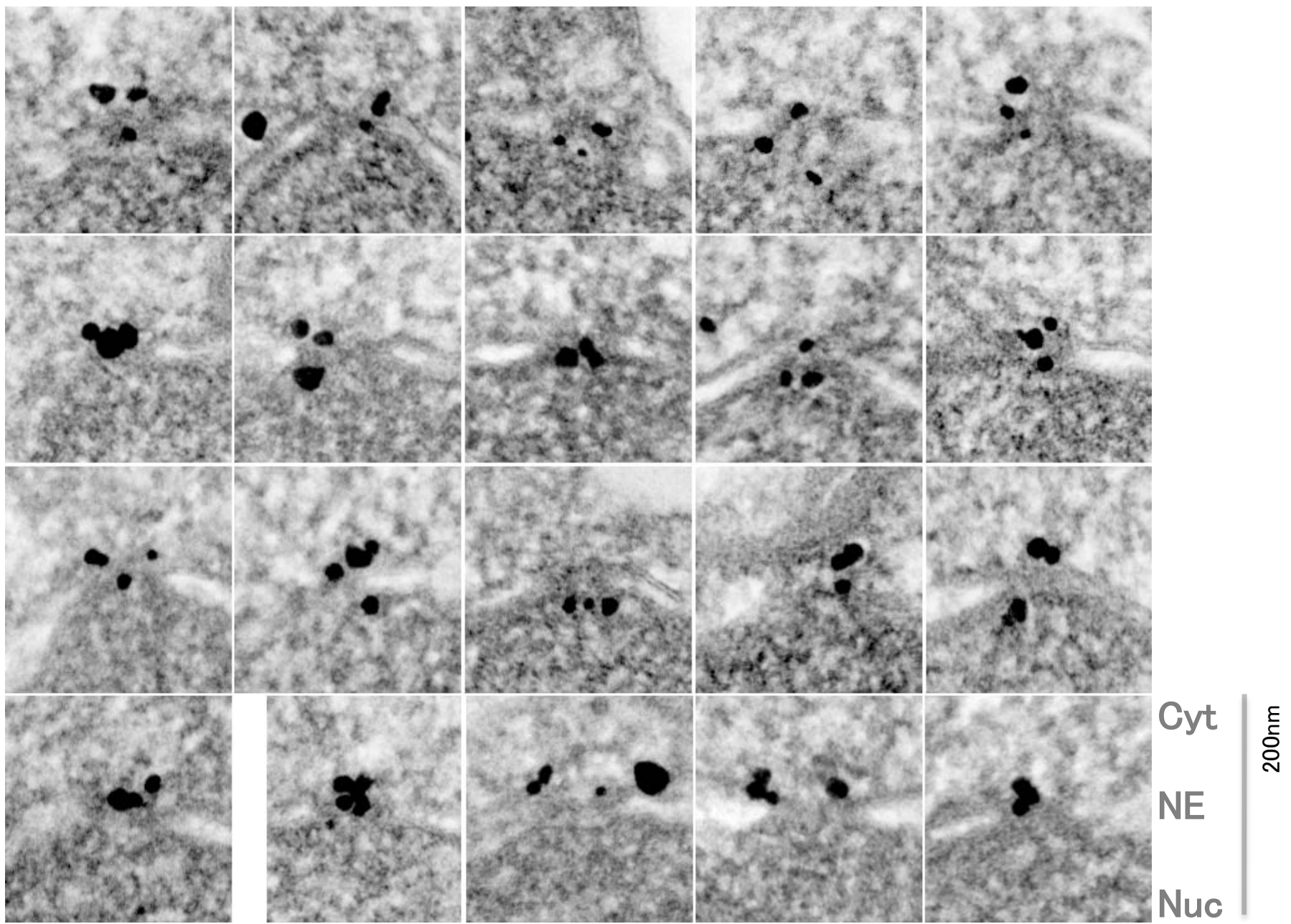


Nup155-GFP

projection

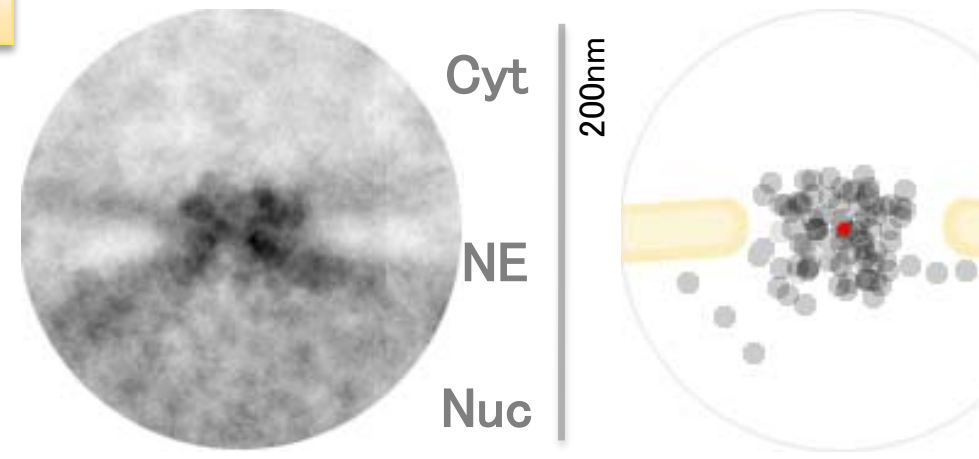

20 NPCs

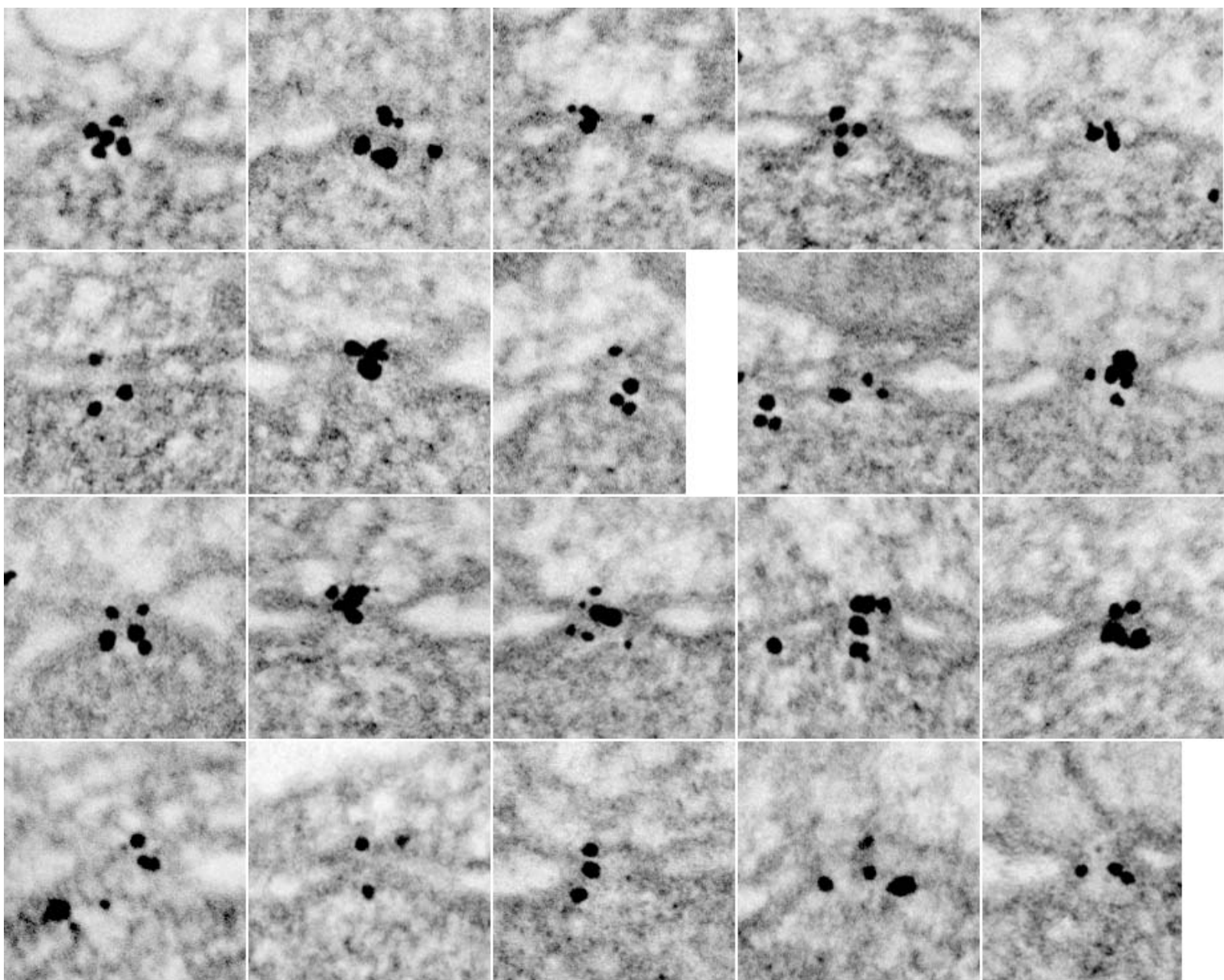

Cyt NE Nuc 


\section{Channel Nups}

Nup44,Nup45, Nup98, Nsp1 
projection

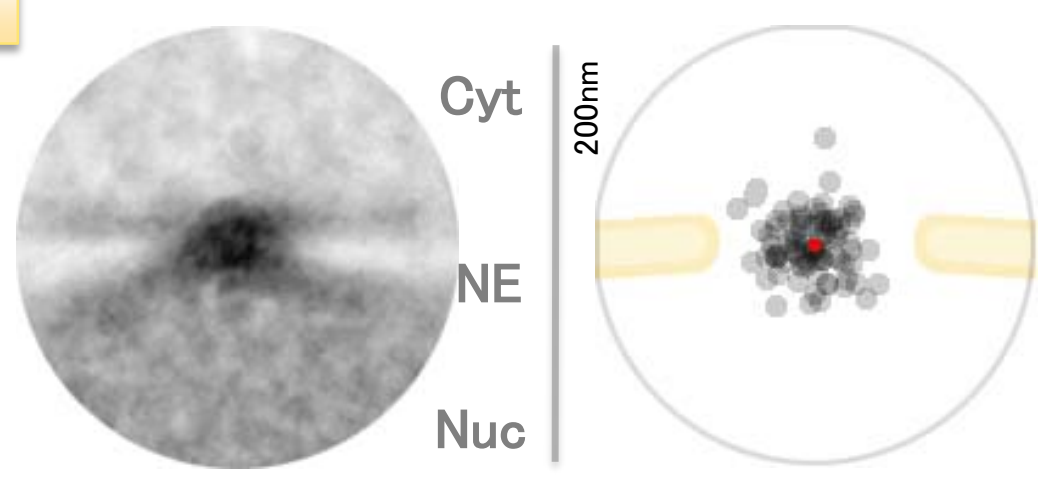

20 NPCs

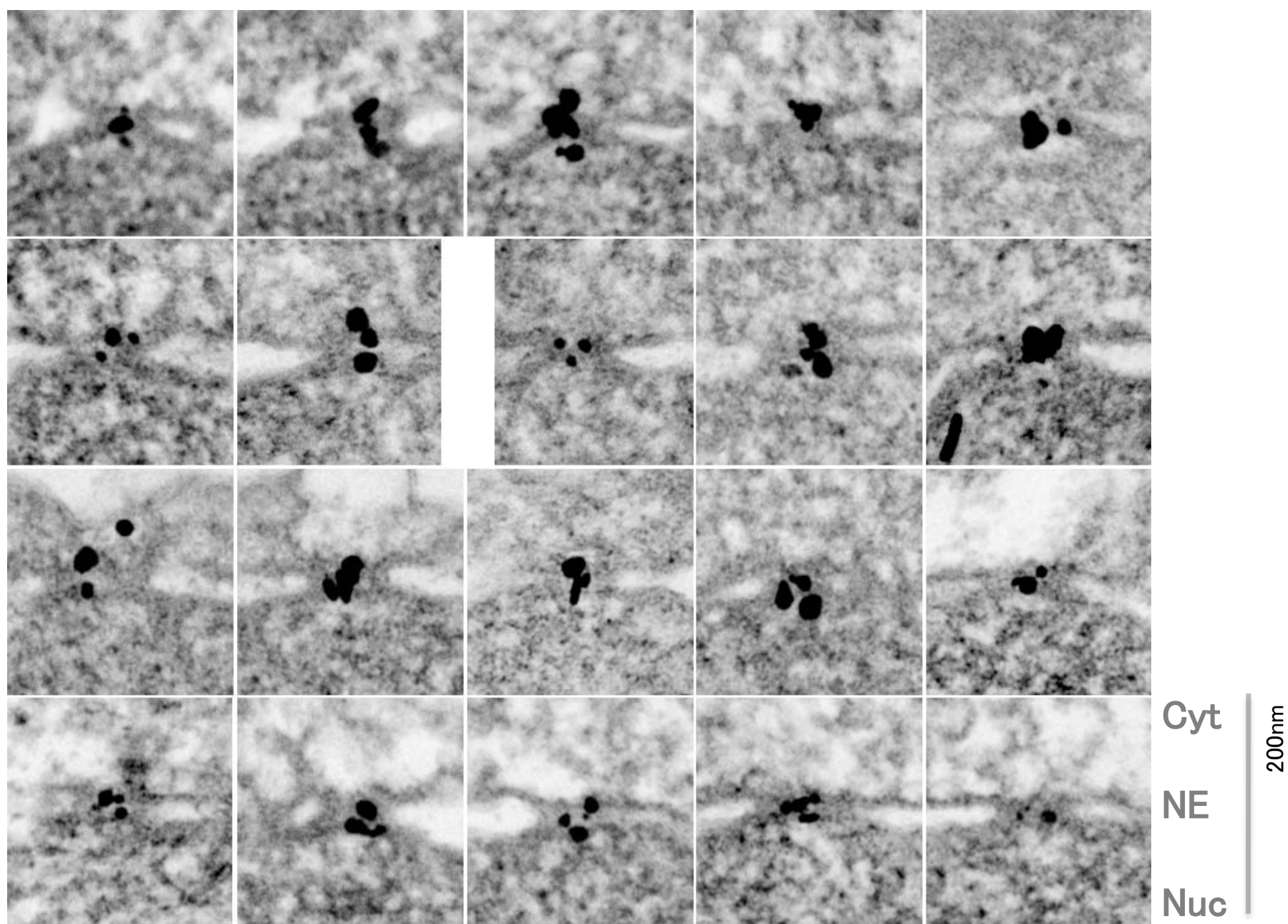


projection

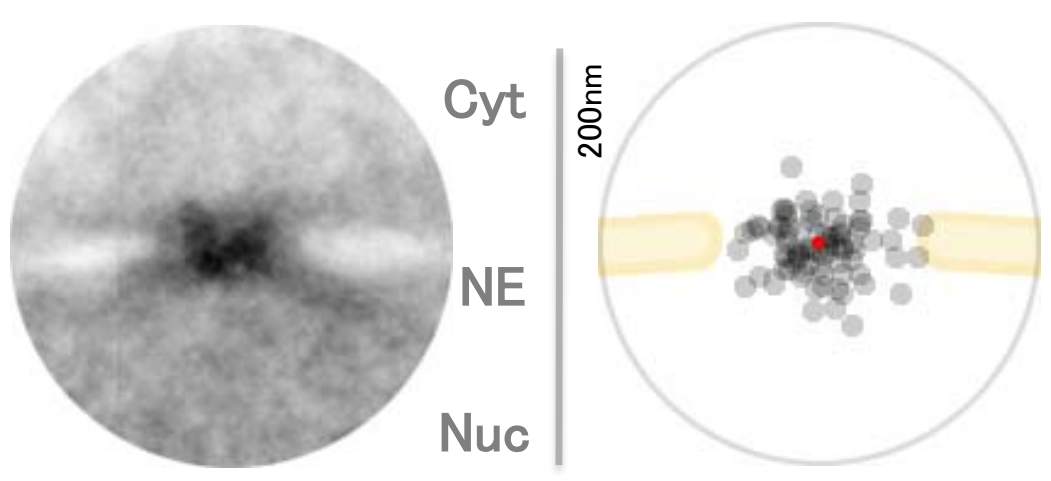

$20 \mathrm{NPCs}$
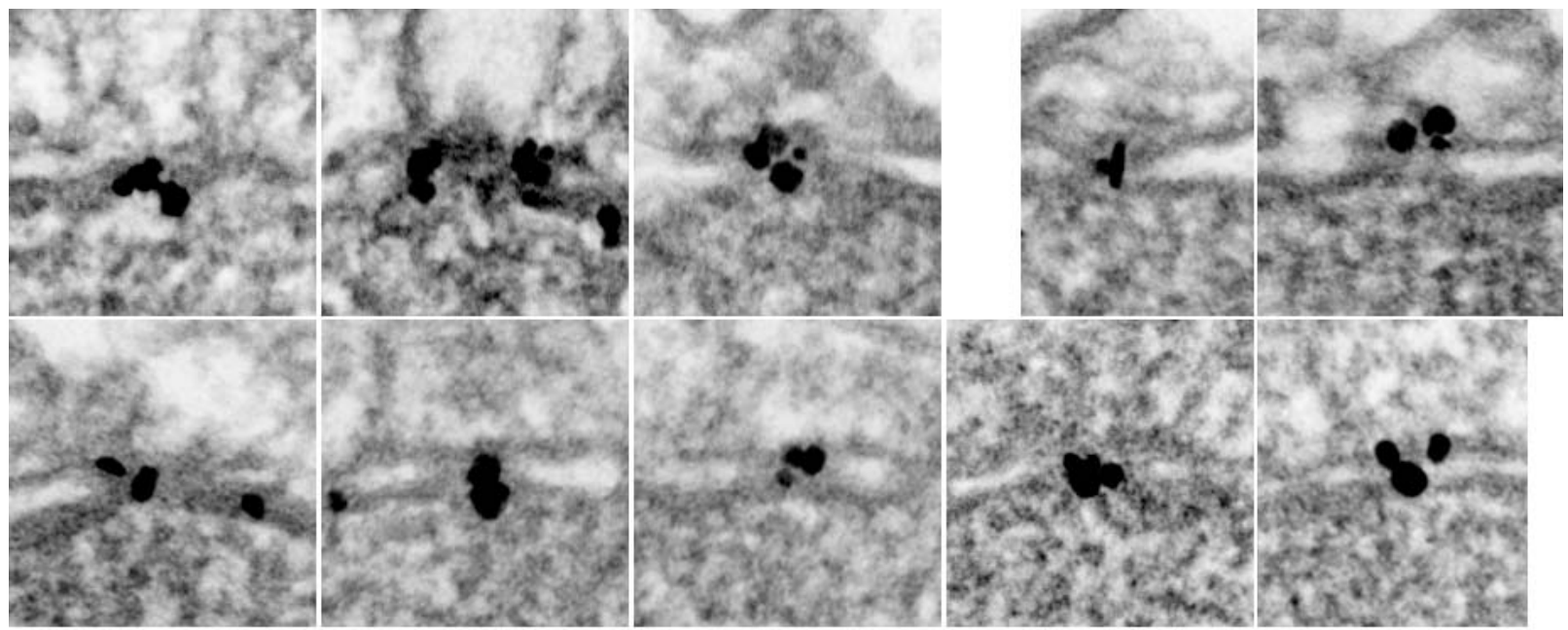

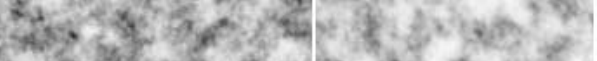

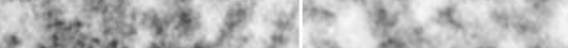
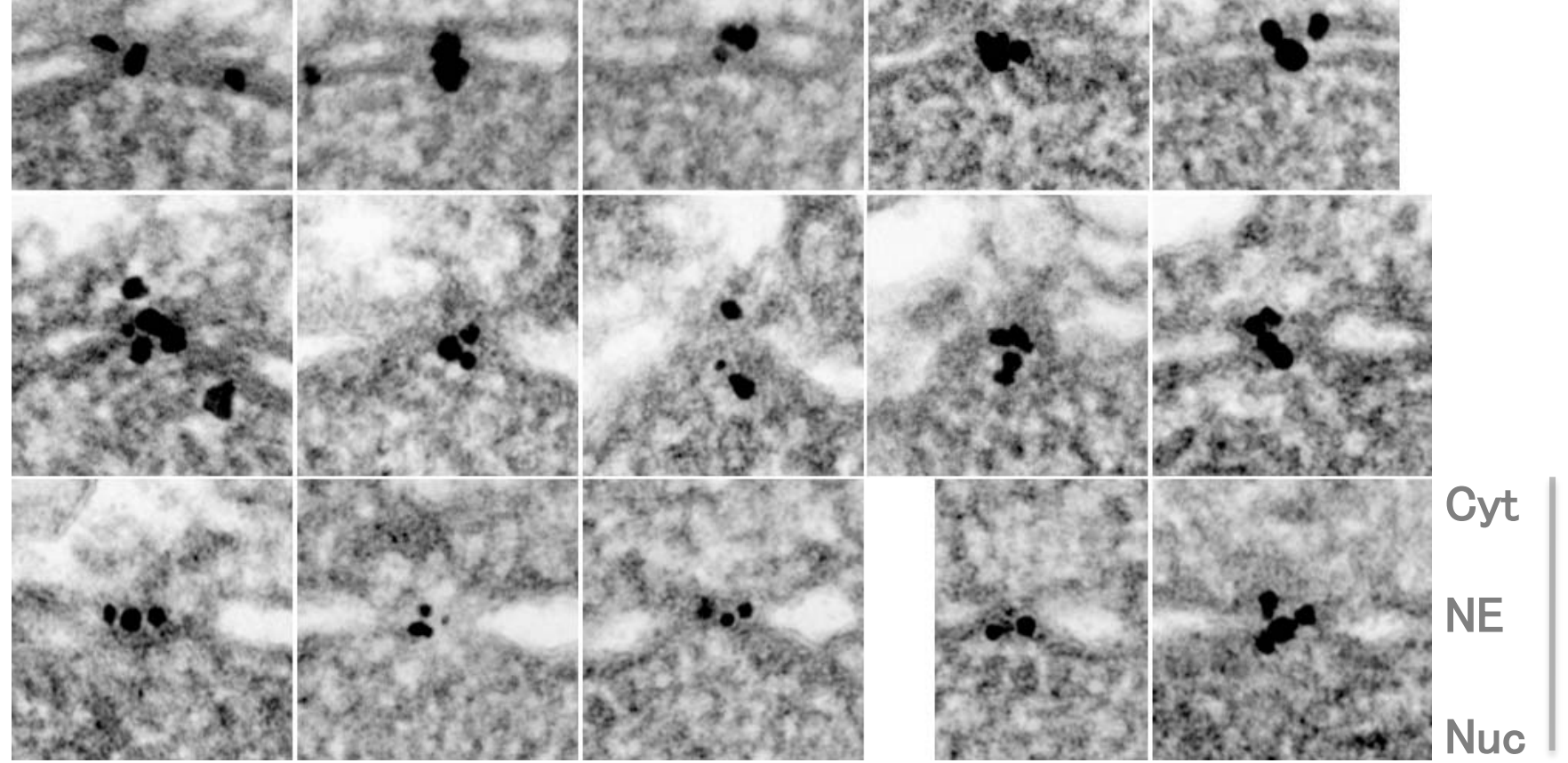
Nup98-GFP

projection

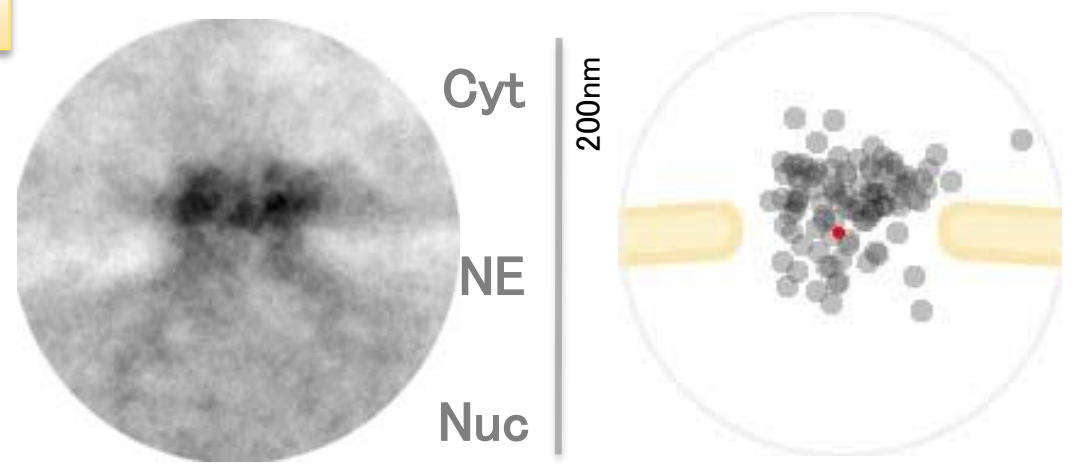

20 NPCs

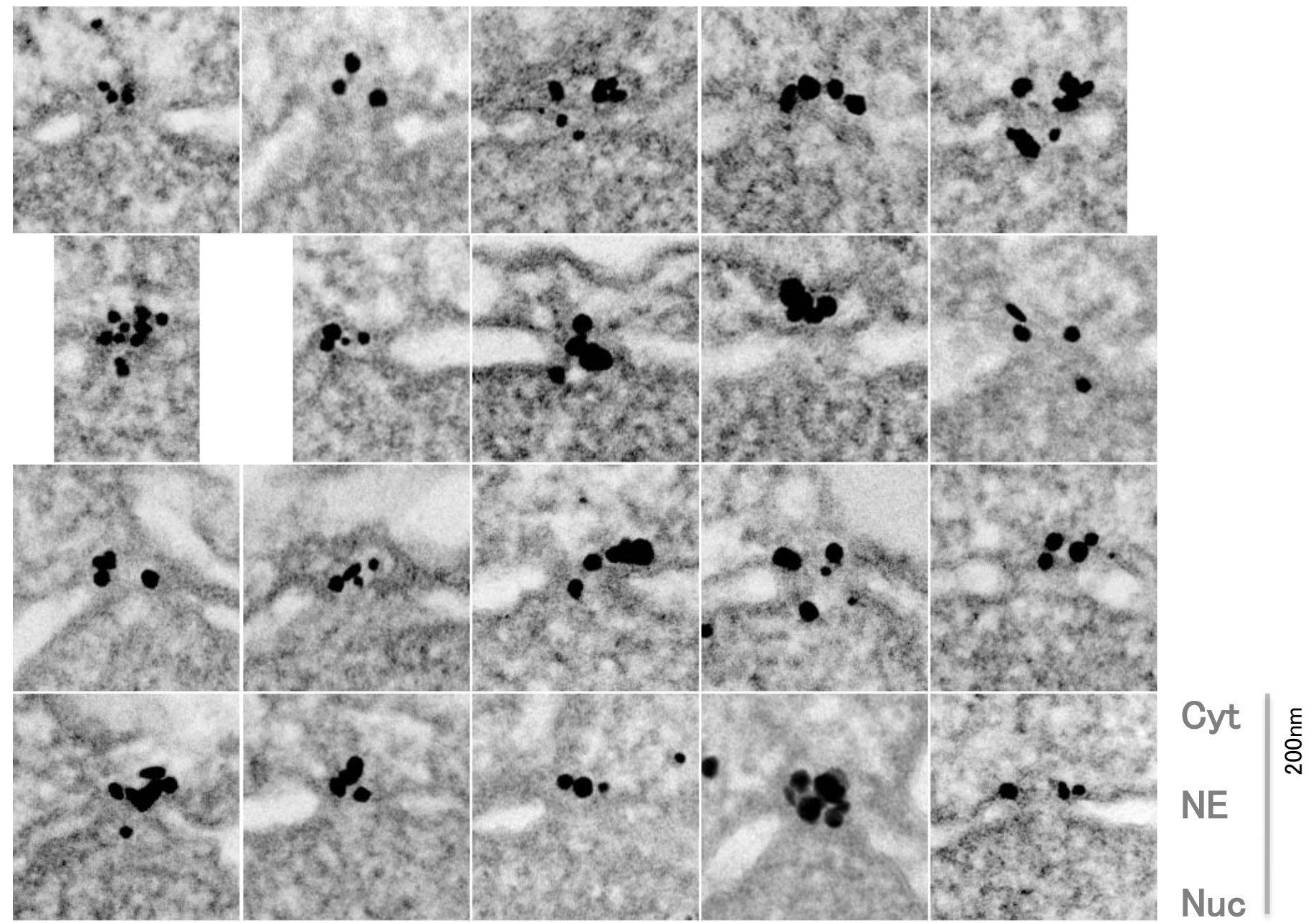




\section{Nup98 \\ (anti-Nup98)}

projection

20 NPCs
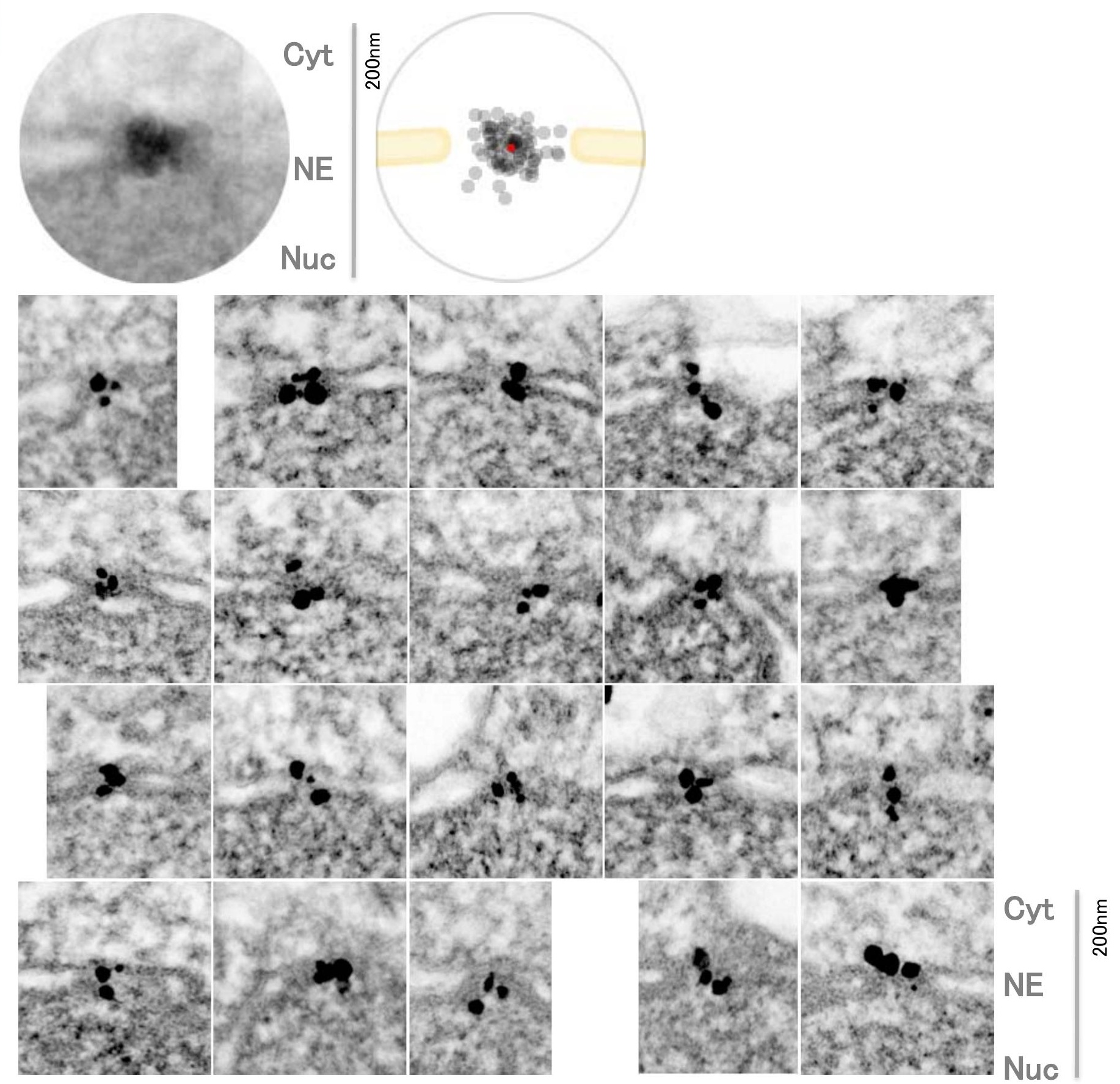


\section{GFP-Nsp1}

projection

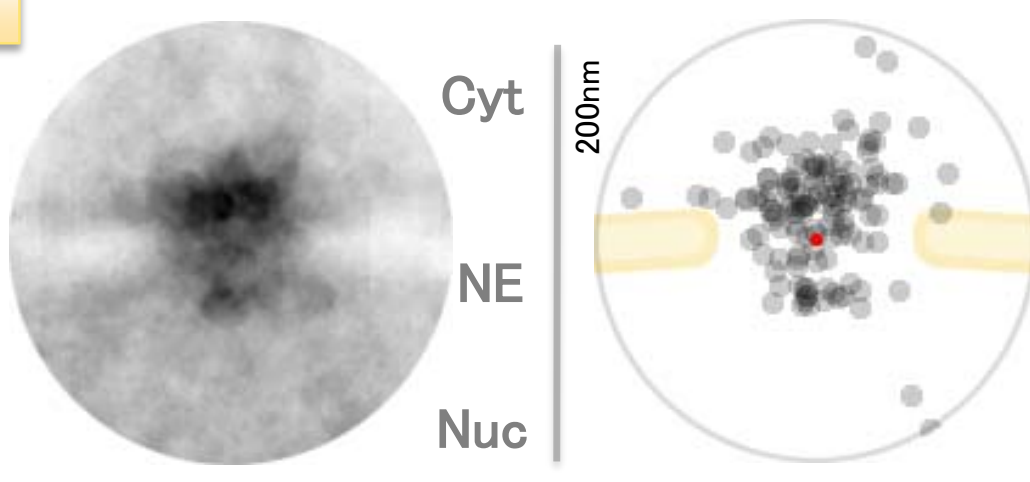

$20 \mathrm{NPCs}$
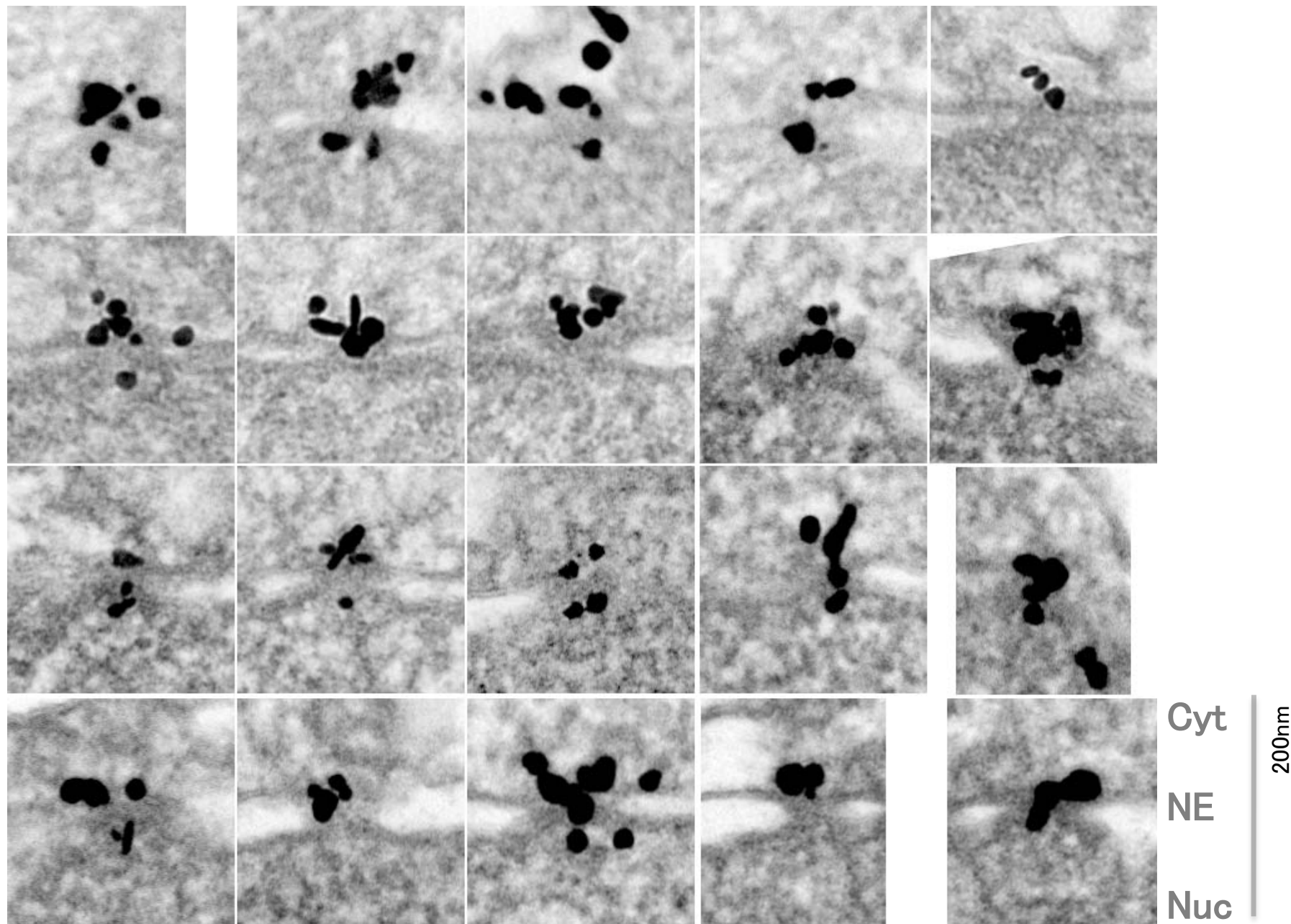


\section{Cytoplasmic ring Nups}

Nup82, Nup146 


\section{Nup82-GFP}

projection

20 NPCs
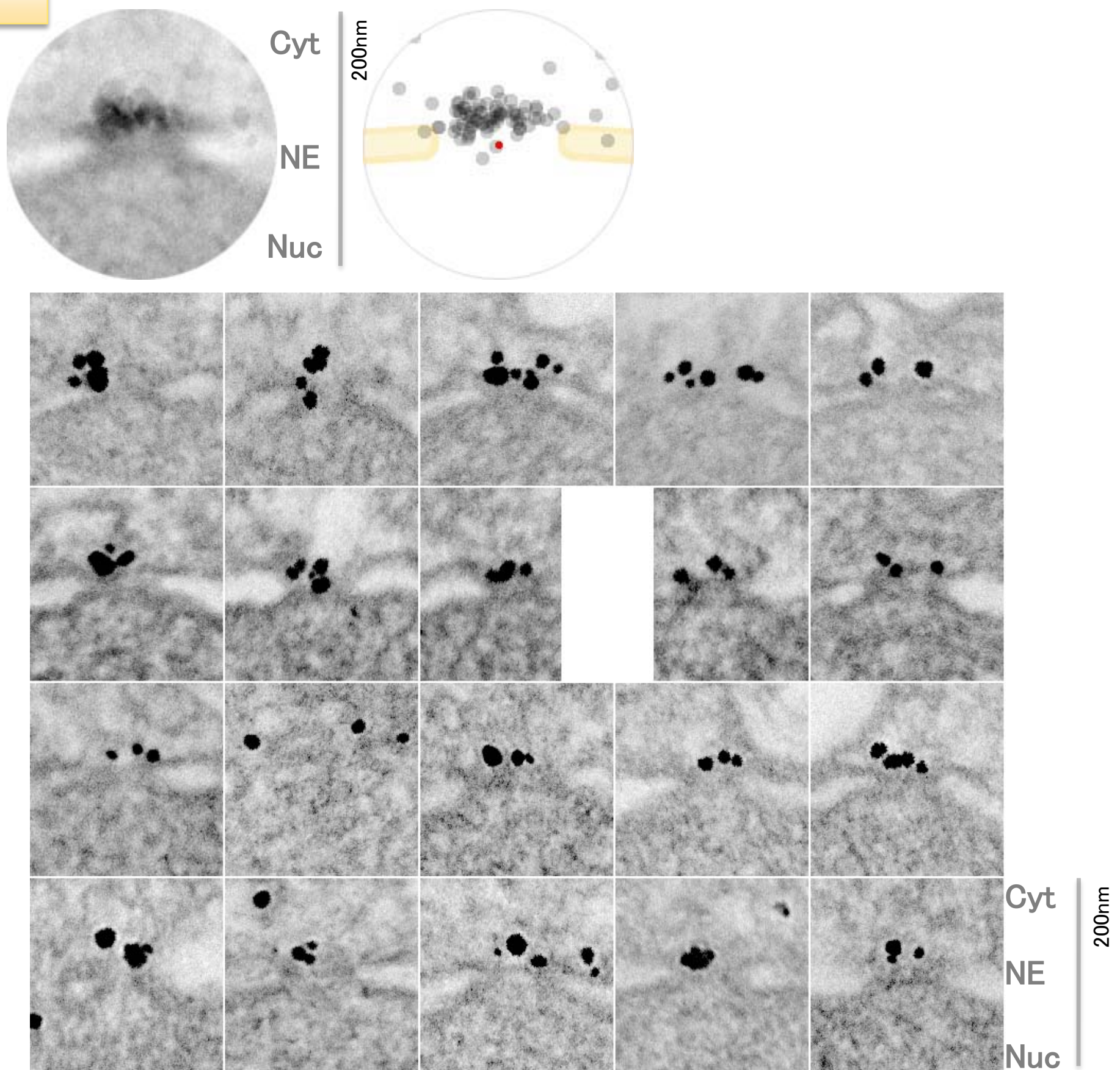


\section{Nup146-GFP}

projection

$20 \mathrm{NPCs}$
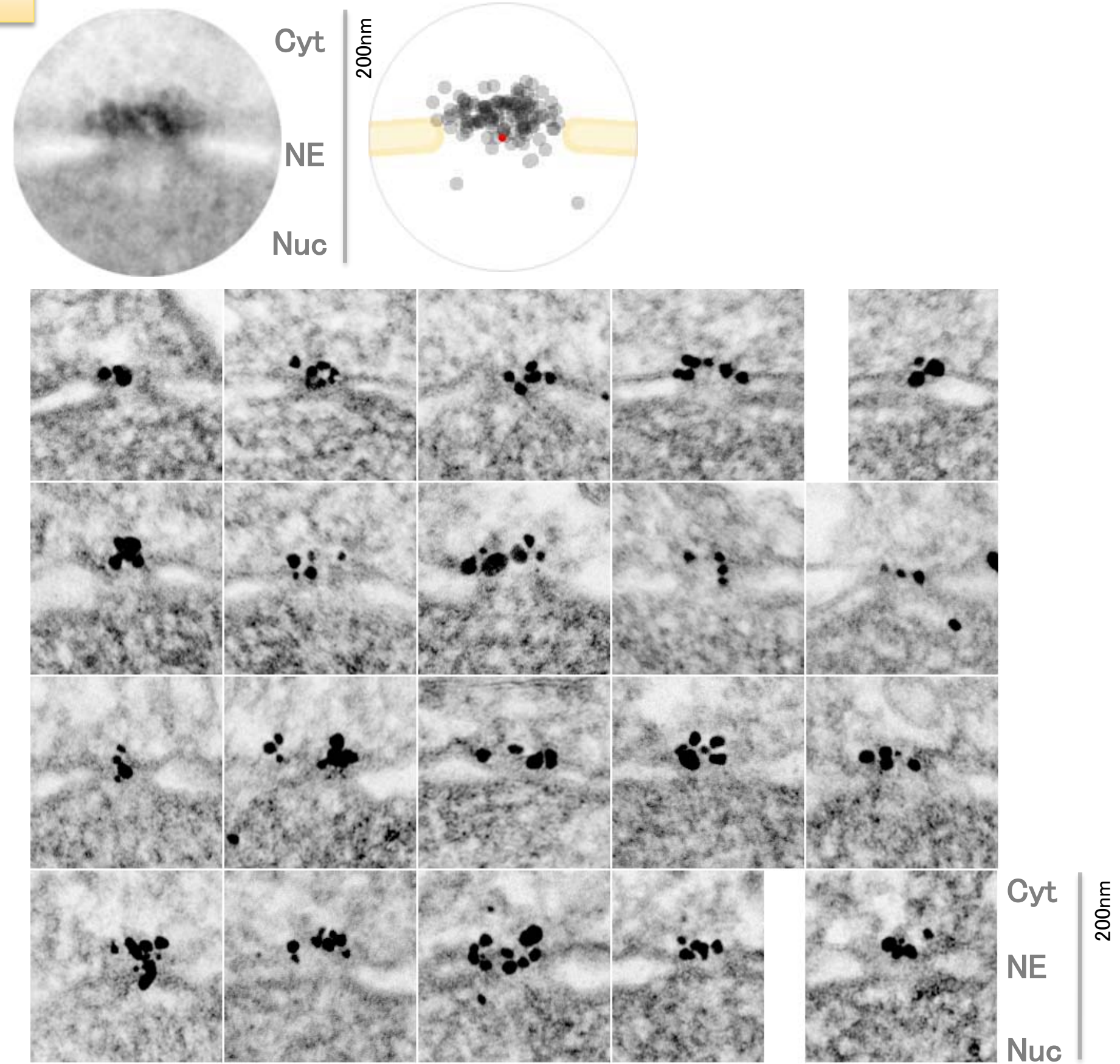
Amo1-GFP

projection

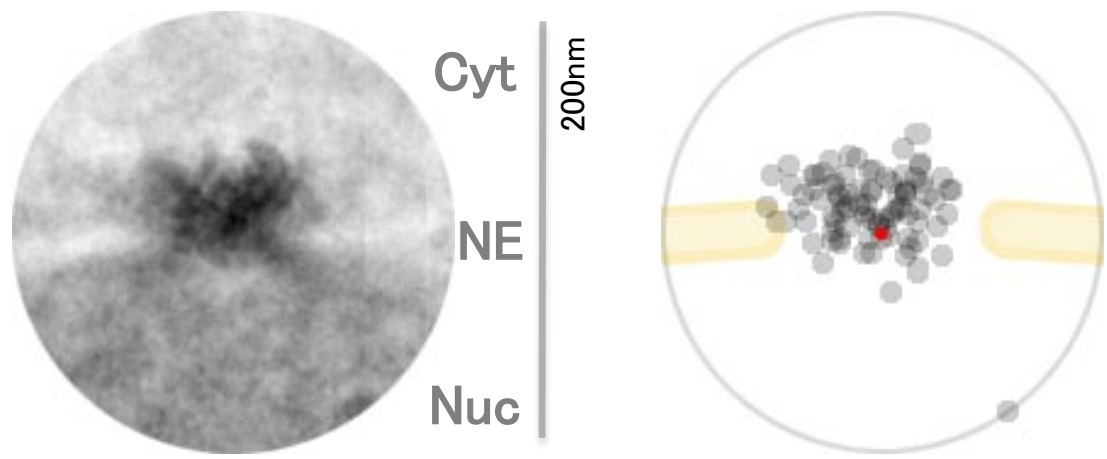

20 NPC

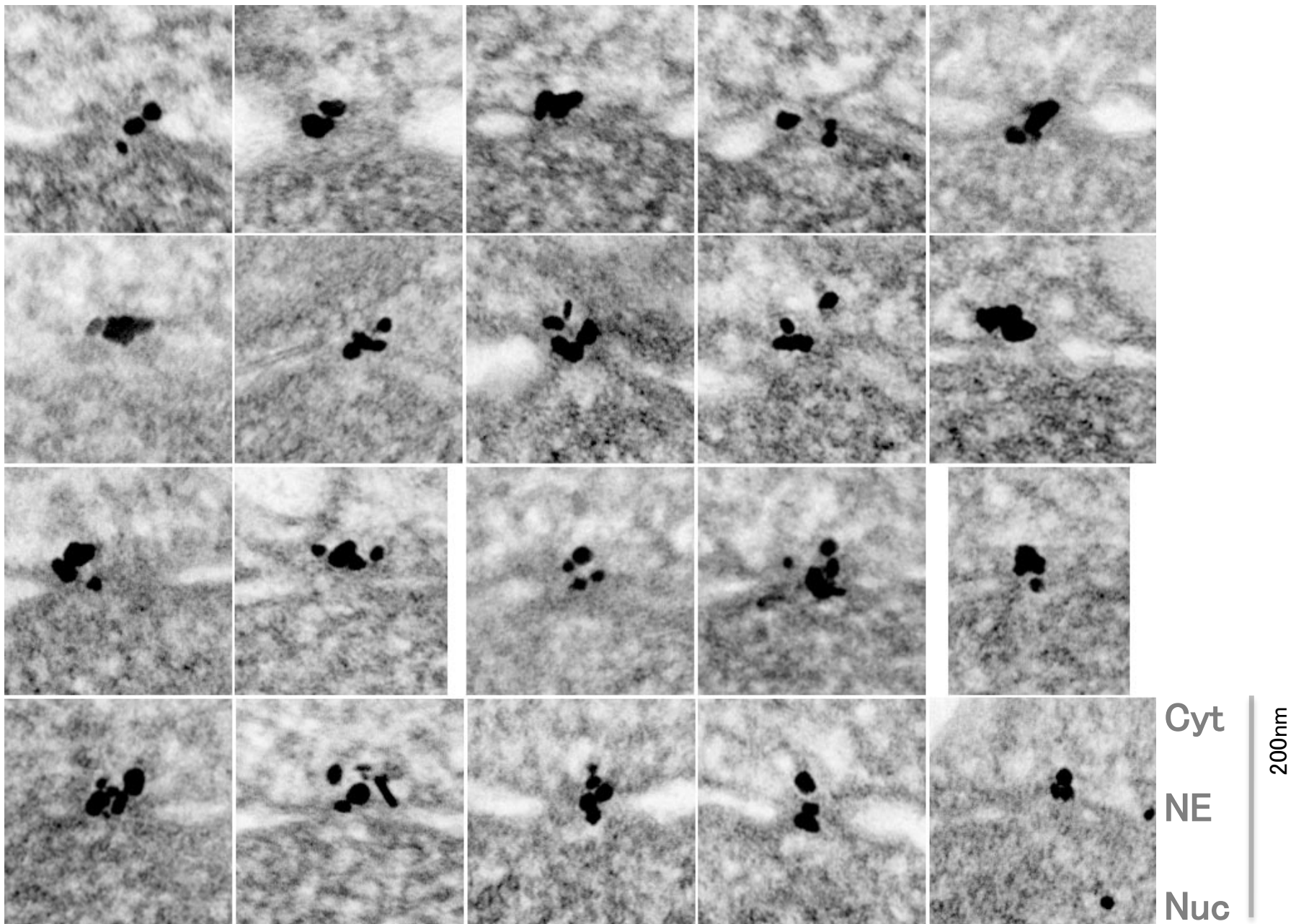


Transmembrane Nups

Cut11, Pom152, Pom34 
Cut11-GFP

projection

20 NPCs
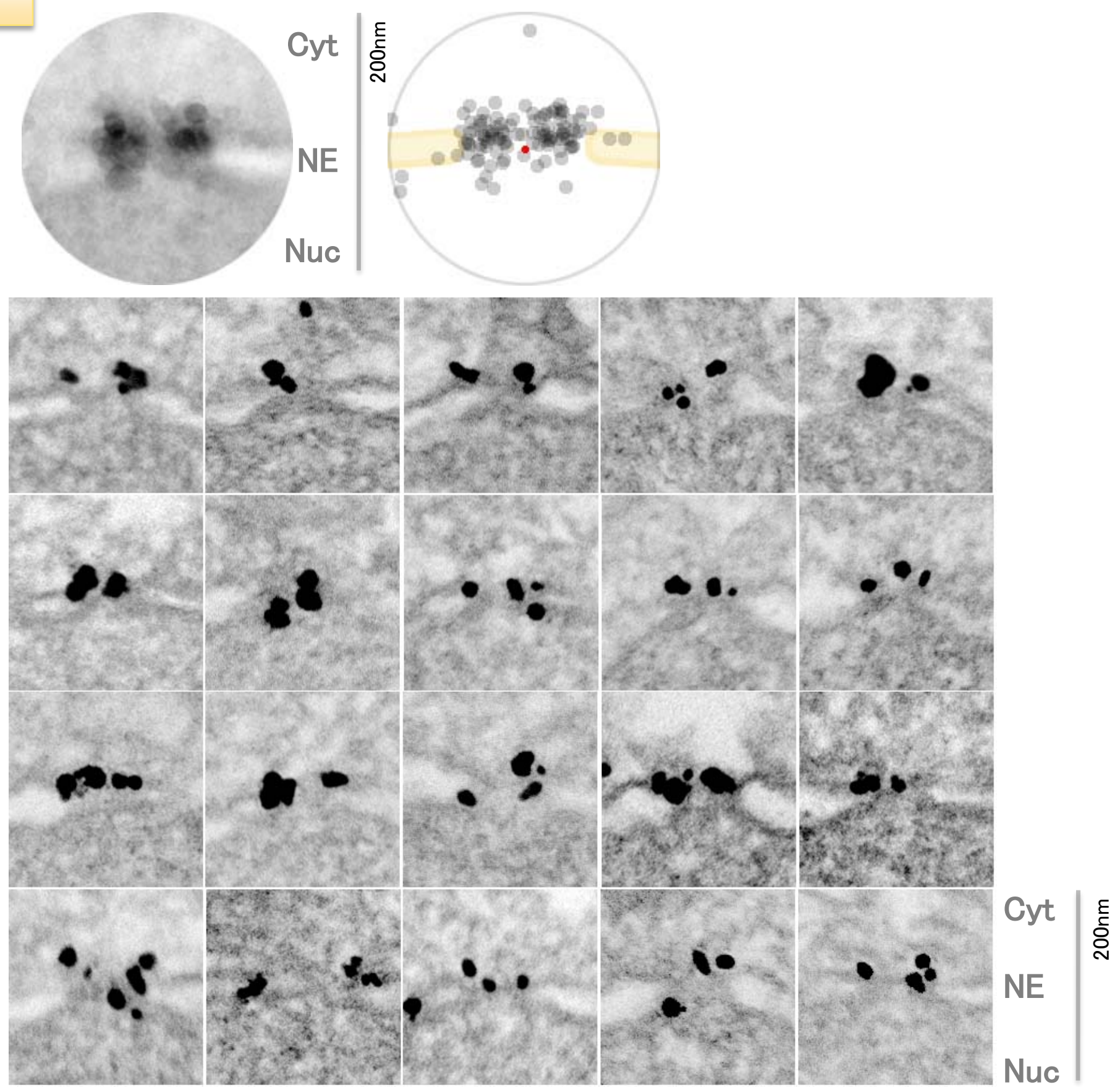


\section{Pom152-GFP}

projection

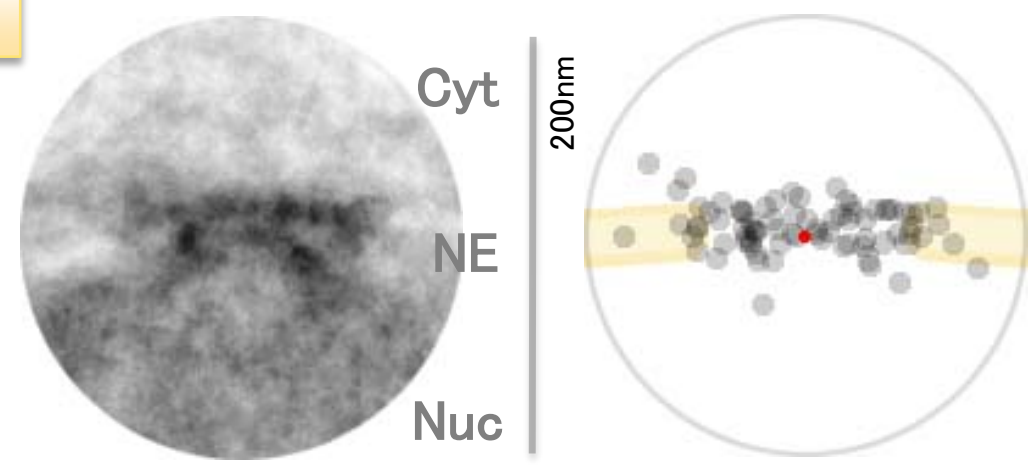

20 NPCs
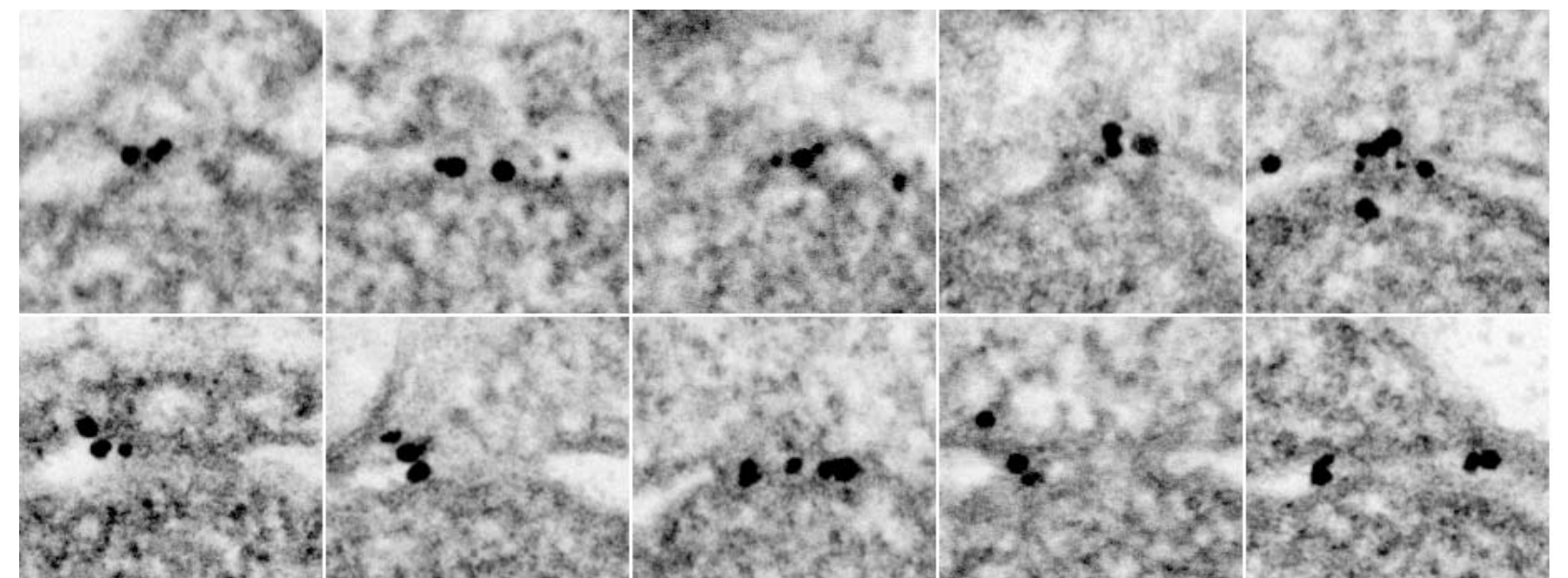

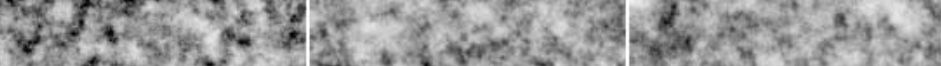

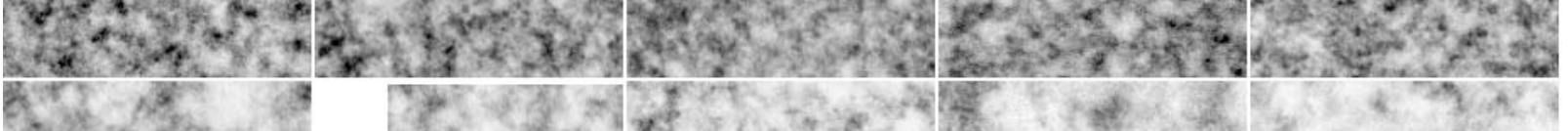

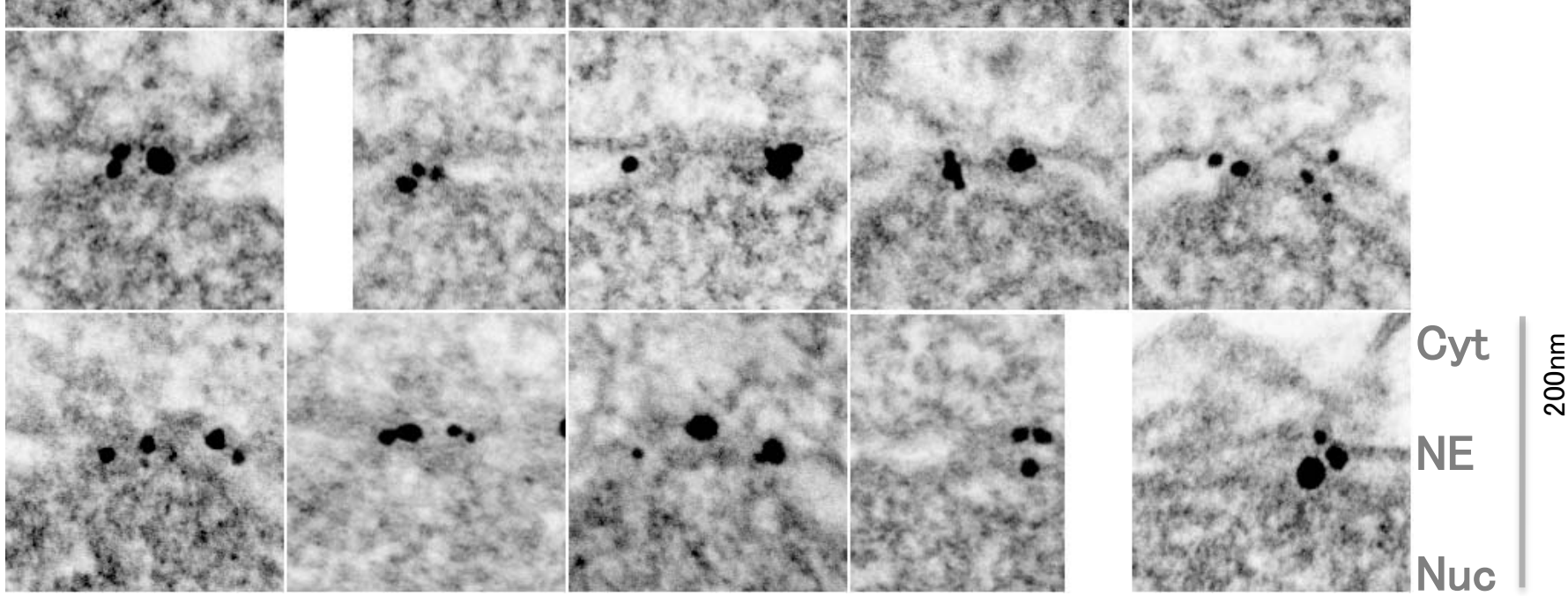

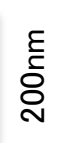




\section{Pom34/Mug31-GFP}

projection

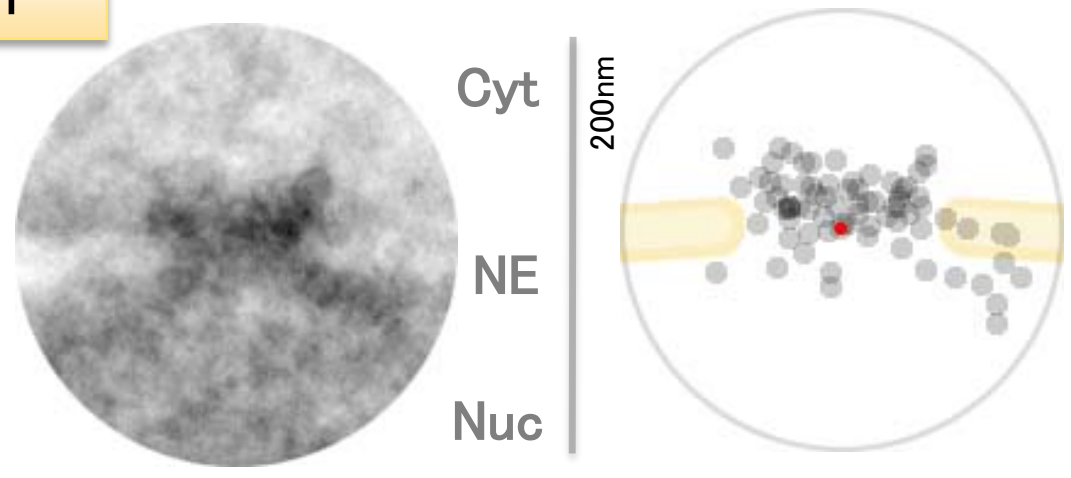

20 NPCs

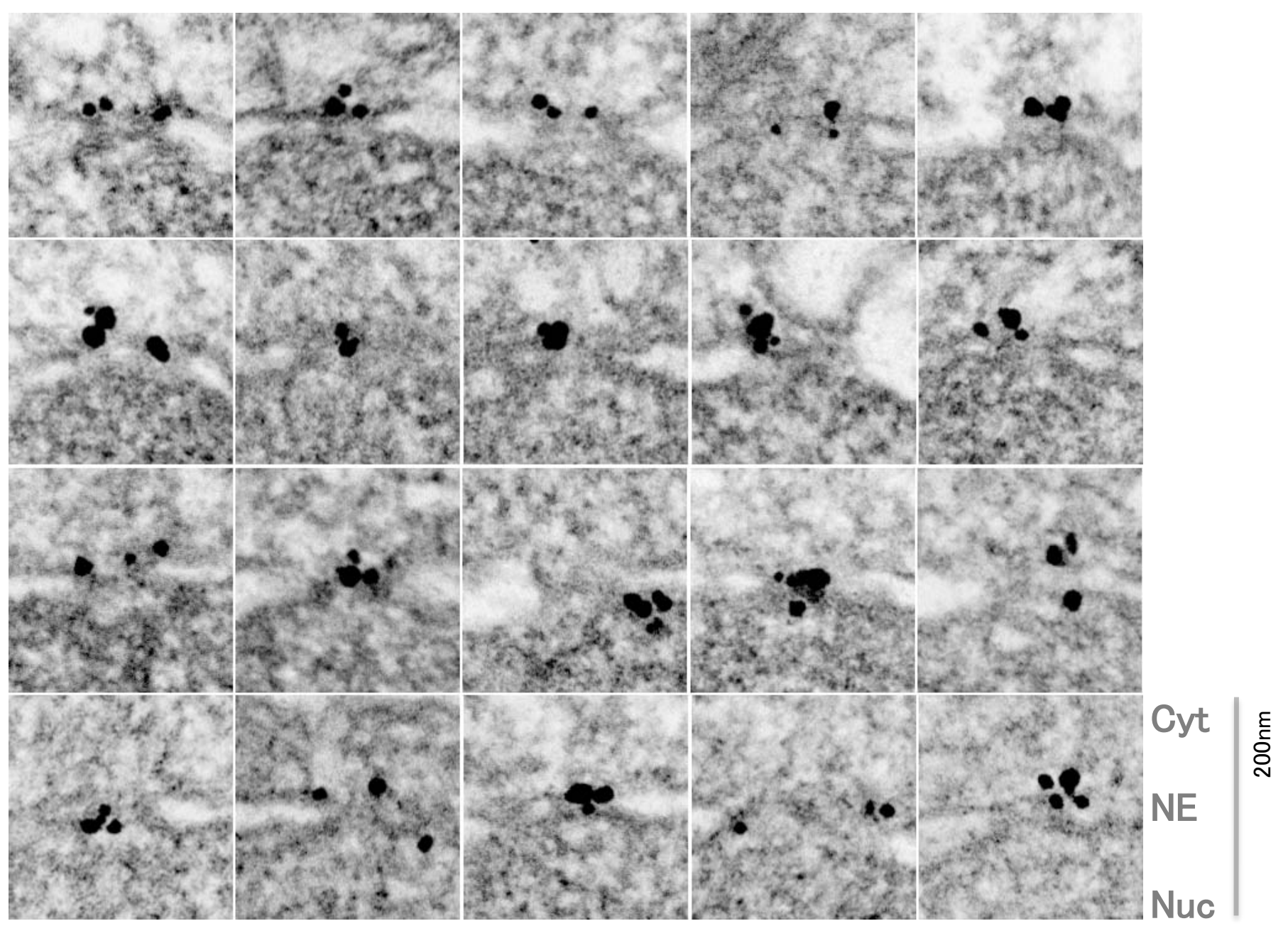




\section{Nuclear basket Nups}

Nup60, Nup61, Nup124, Alm1 
Nup60-GFP

projection

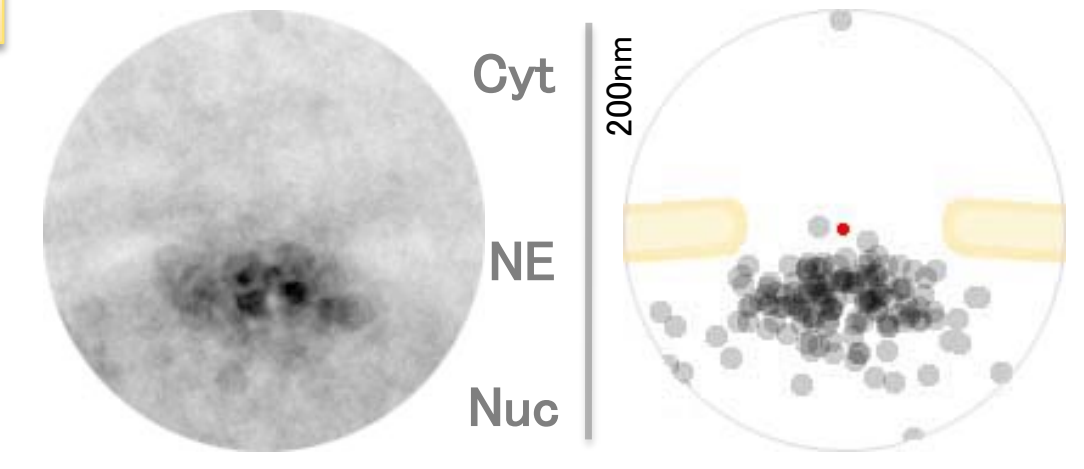

\section{NPCs}

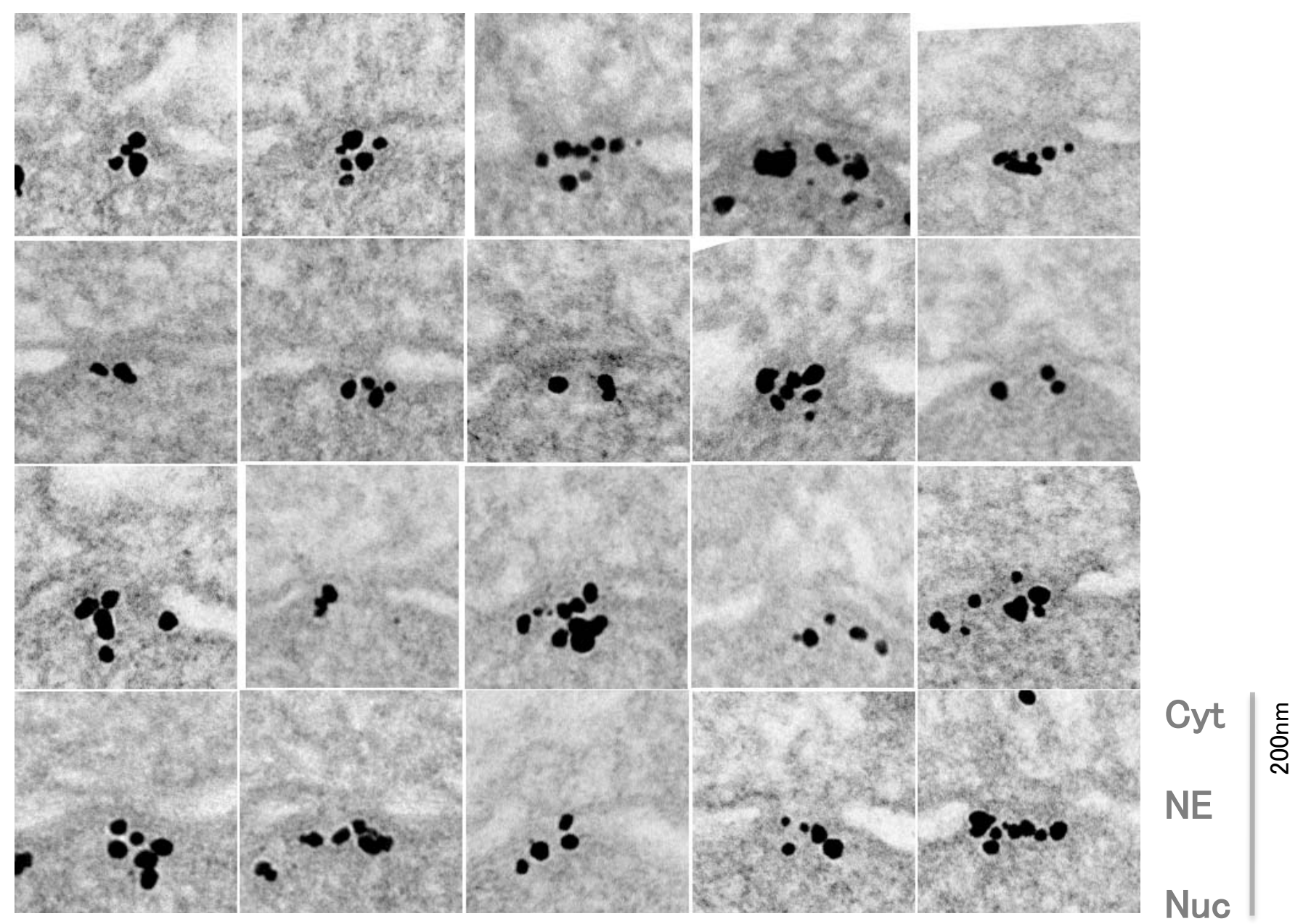


GFP-Nup61

projection

20 NPCs
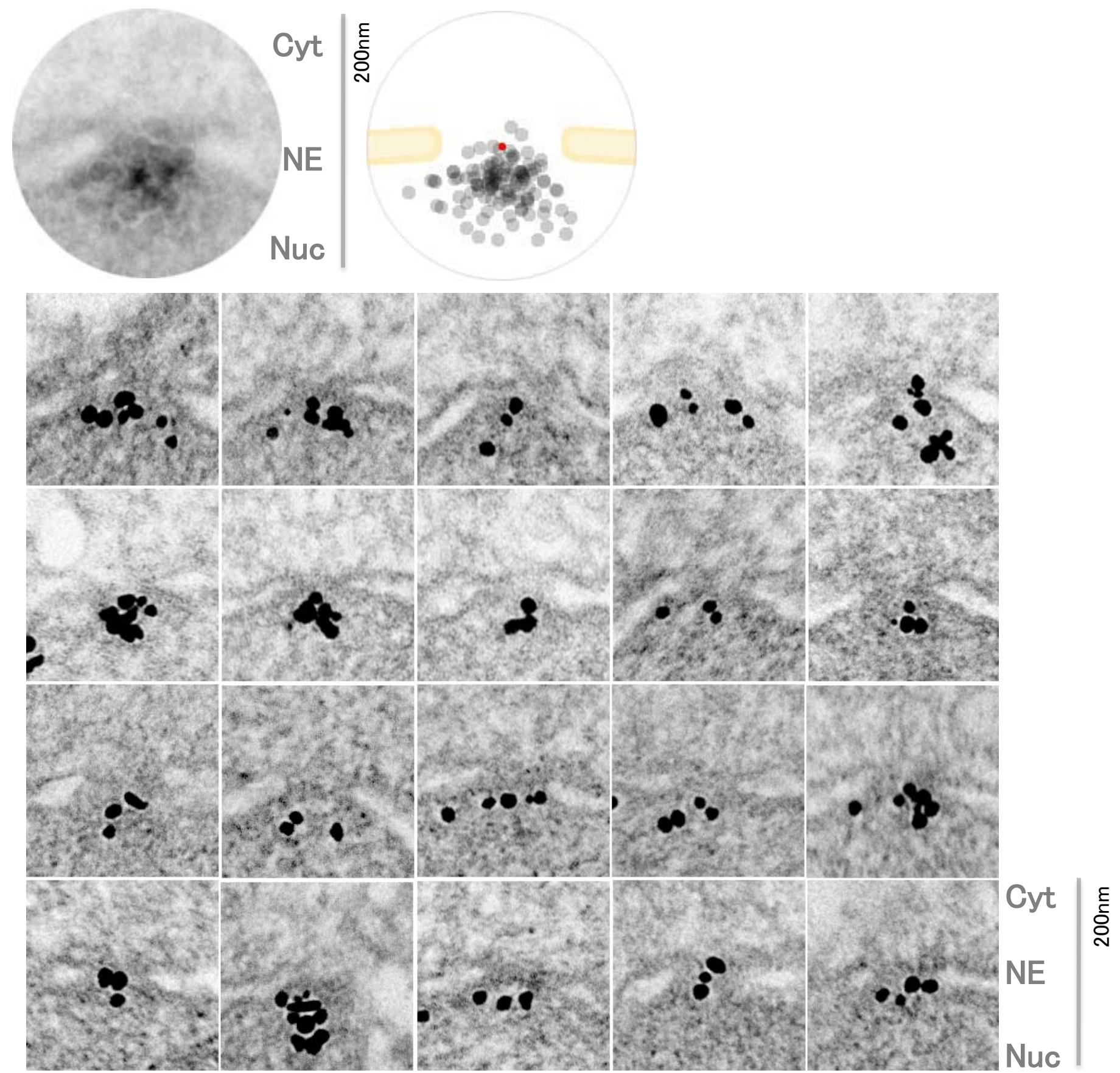
projection

$20 \mathrm{NPCs}$
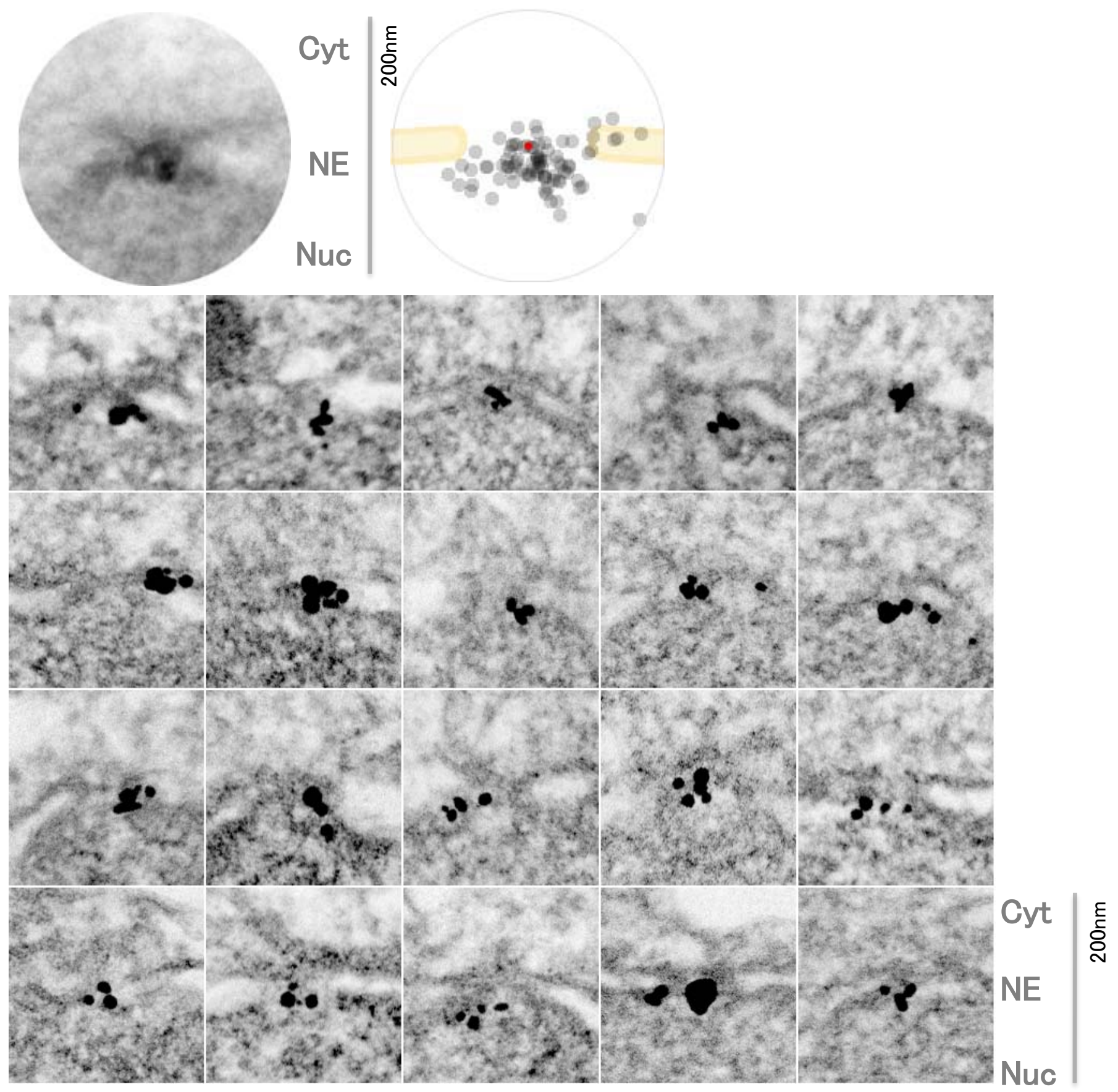


\section{Alm1-GFP}

projection

$20 \mathrm{NPCs}$
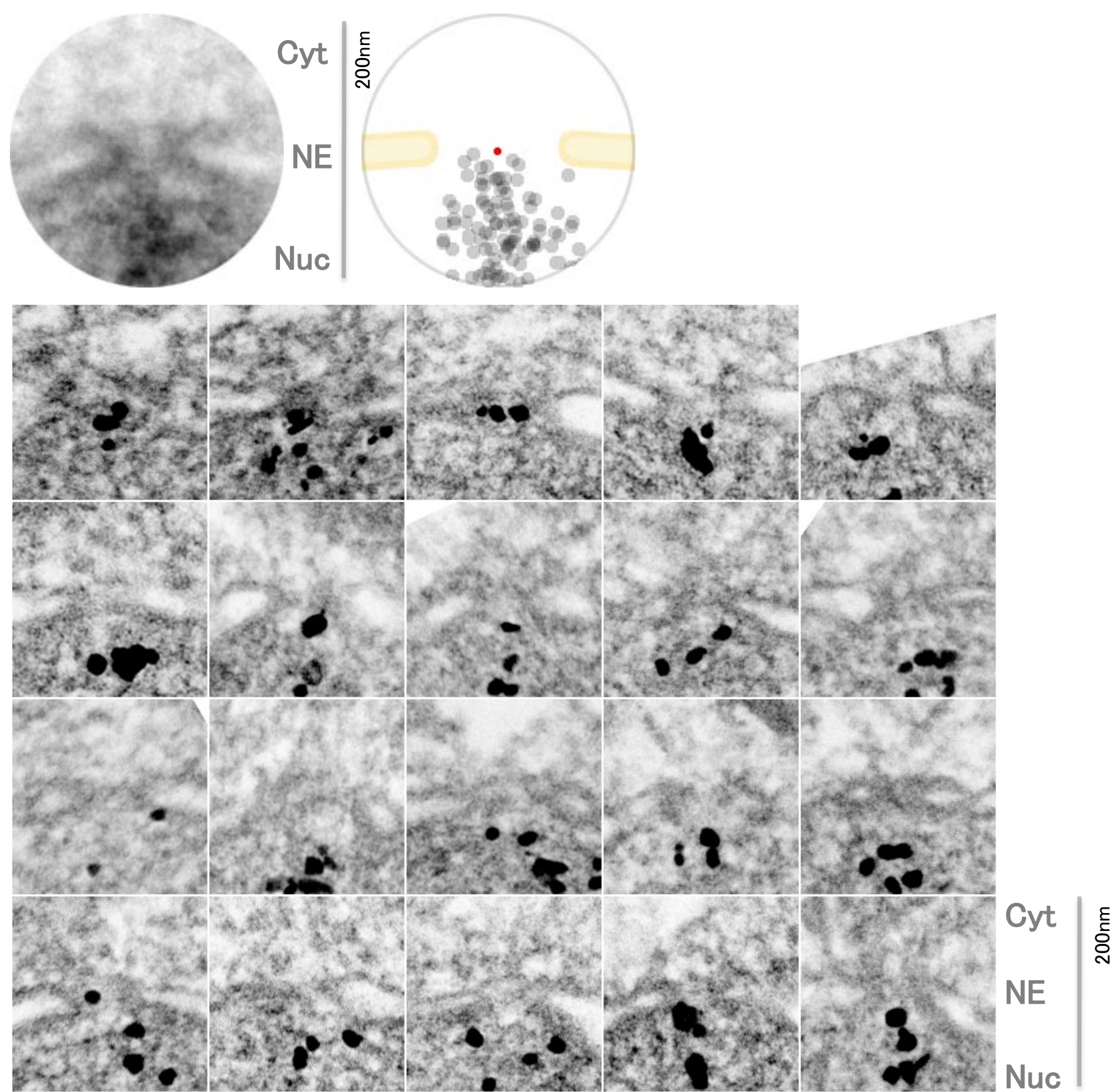